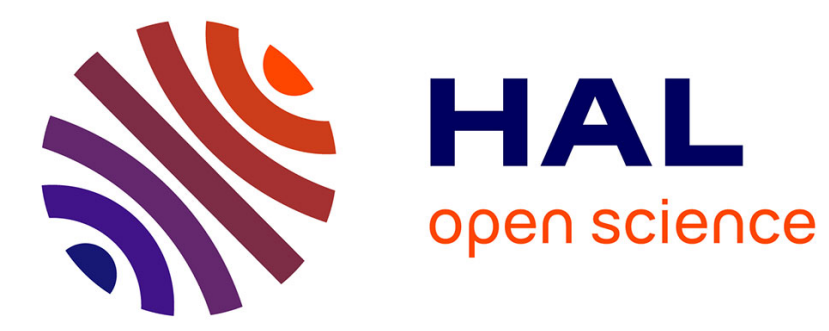

\title{
The Molecular Basis of the Adsorption of Bacterial Exopolysaccharides on Montmorillonite Mineral Surface.
}

\author{
Lina Henao, Karim Mazeau
}

\section{To cite this version:}

Lina Henao, Karim Mazeau. The Molecular Basis of the Adsorption of Bacterial Exopolysaccharides on Montmorillonite Mineral Surface.. Molecular Simulation, 2008, 34 (10-15), pp.1185-1195. 10.1080/08927020802235714 . hal-00515045

\section{HAL Id: hal-00515045 \\ https://hal.science/hal-00515045}

Submitted on 4 Sep 2010

HAL is a multi-disciplinary open access archive for the deposit and dissemination of scientific research documents, whether they are published or not. The documents may come from teaching and research institutions in France or abroad, or from public or private research centers.
L'archive ouverte pluridisciplinaire HAL, est destinée au dépôt et à la diffusion de documents scientifiques de niveau recherche, publiés ou non, émanant des établissements d'enseignement et de recherche français ou étrangers, des laboratoires publics ou privés. 


\section{Molecular Simulation}

Journal of

Experimental Nanoscience

Taylor \& Francis

Taglor \& Francis Group

The Molecular Basis of the Adsorption of Bacterial Exopolysaccharides on Montmorillonite Mineral Surface.

\begin{tabular}{|r|l|}
\hline Journal: & Molecular Simulation/Journal of Experimental Nanoscience \\
\hline Manuscript ID: & GMOS-2008-0064.R1 \\
\hline Journal: & Molecular Simulation \\
\hline Date Submitted by the \\
Author: & $14-$ May-2008 \\
\hline Complete List of Authors: & $\begin{array}{l}\text { Mazeau, karim; CNRS, CERMAV } \\
\text { Henao, lina; CNRS, CERMAV }\end{array}$ \\
\hline Keywords: & molecular modeling, clay, polysaccharide \\
\hline
\end{tabular}

\section{SCHOLARONE ${ }^{\text {m }}$ Manuscripts}




\begin{abstract}
Rhizospheric exopolysaccharides (EPS) spontaneously aggregate mineral particles. Molecular dynamics simulations with Cerius2 and Material Studio programs have been performed to study the adsorption of chemical groups, monosaccharides and oligosaccharides, onto the basal surface of Na-montmorillonite. The estimated enthalpies of adsorption of chemical groups nicely reproduced the expected values. Mono- and oligosaccharides have a preferred geometry of adsorption. Monosaccharides maintained their shape upon adsorption whereas oligosaccharides flattened more or less on the surface, depending on their flexibility. The conformational adaptability was shown to be the leading factor that determined the interaction strength between the EPS and the mineral surface.
\end{abstract}

\title{
Introduction
}

Organic/inorganic hybrid composites are materials that comprise nanometer-size mineral particles dispersed in a polymer matrix. Compared to pure matrix, these materials exhibit enhanced properties : an increase of the mechanical and thermal performances, and a barrier effect to gas diffusion[1, 2]. Most of the matrices considered so far are synthetic polymers; preparing such materials is difficult because of the low compatibility between hydrophobic polymers and the hydrophilic mineral. To overcome this difficulty, the cations located in the interlayer space of the clays are exchanged by tensioactive molecules (principally alkyl ammoniums). The inter layer space thus gain a hydrophobic character and become compatible with polymers.

Such hybrid complexes do exist in nature; rhizospheric microorganisms, i.e. living in the vicinity of plant roots, produce exo-polysaccharides (EPS); these EPS possess two key properties: they aggregate mineral particles[3] and they can retain a large amount of water[4]. The benefit for bacteria is obvious as they are protected by organo-mineral aggregates against 
both brutal climatic changes and hydric stress[4-10]. There is also a benefit for the soil, as the presence of aggregates is correlated with soil fertility[11]. Polysaccharides have indeed the additional properties of being biocompatible and biodegradable, two supplementary advantages exploited in an emerging class of biomaterials[12-17].

The macroscopic properties reflect the associations occurring at the molecular scale between polysaccharides, mineral particles and water. The surface of montmorillonite for example, bears negative charges; one may intuitively think that the most favorable organic molecules for adsorption onto such mineral are poly-cations. The situation is apparently more complicated as many rhizospheric EPS are shown to interact with minerals[6, 18-24]; they are either neutral or anionic (with one or two charges per repeat unit, generally carboxylic acids). The role of the fine structure of the polysaccharide on its adsorption mechanism onto mineral surfaces remains largely unclear. However, EPS offer a unique opportunity to establish structure-property relationships; their experimental responses to flocculate a colloidal suspension of clays are effectively structure dependant[25, 26] and EPS possess a wide variety of structures: they can be linear or branched. When present, the ionisable group is located either on the backbone or on the side chains (see figure 1). To complement the experimental efforts, our objective was thus to reveal, by molecular modeling, the structural factors (if any) of microbial polysaccharides that are responsible for their adsorption on mineral surfaces. Montmorillonite is the chosen mineral; it is widespread on earth, its crystal structure is reported[27] and it is widely studied by molecular modeling (in particular in interactions with organic species)[28-32]. Only the basal surface of montmorillonite was considered in this study as it is statistically the most abundant surface.

\section{Material and Methods.}

In this study, we have used the modeling softwares Cerius ${ }^{2}$ and Material studio (accelrys inc.) running on silicon graphics workstations at the Centre d'Expérimentation et de Calcul Intensif, CECIC, Grenoble, France.

\section{Construction of the initial structures.}

Mineral surface.

Montmorillonite is a smectite type mineral clay, it is a hydrophilic mineral that consists of a nanometer-thick layers formed by sandwiching an aluminum octahedron sheet between two silicon tetrahedron sheets. The initial unit cell was built from relevant crystallographic coordinates of a pyrophillite crystal, published by Tsipursky and Drits[27], using the Crystal 
Builder modulus. The experimental lattice is monoclinic, with space group $\mathrm{C} 2 / \mathrm{m}$, and the lattice parameters: $a=5.20, b=9.20, c=10.13$ and $\alpha=90^{\circ}, \beta=99^{\circ}, \gamma=90^{\circ}$. The unit cell is duplicated along the two directions parallel to the sheet planes. Then, we performed substitution of some $\mathrm{Al}^{3+}$ by $\mathrm{Mg}^{2+}$ in the octahedral layer and substitution of some $\mathrm{Si}^{+4}$ atoms by $\mathrm{Al}^{3+}$ in the tetrahedral layer in order to obtain the desired final chemical composition of the Wyoming Na-montmorillonite : $\mathrm{Na}_{0.75}\left(\mathrm{Si}_{7.75} \mathrm{Al}_{0.25}\right)\left(\mathrm{Al}_{3.5} \mathrm{Mg}_{0.5}\right) \mathrm{O}_{20}(\mathrm{OH})_{4}$. This structure has a cation exchange capacity (CEC) of $1.01 \mathrm{meq} / \mathrm{g}$; the CEC is defined as the amount of the exchangeable cations retained by the clay to neutralize the negative charge (milliequivalent of positive charge per gram of clay). Periodic boundary conditions are applied in all the three dimensions. Typical $a, b$ dimensions of the periodic cell are $17.8 \AA$ x $30.4 \AA$, corresponding to a surface area of $5.4 \mathrm{~nm}^{2}$. This surface was used to study the adsorption of small molecules (chemical functions and monosaccharides). A larger surface was also built to model the adsorption of the largest structures (oligomers). Cell parameters of the large surface model were $72.8 \AA$ x $62.1 \AA$, (area of $45 \mathrm{~nm}^{2}$ ). The clay mineral is then minimized, equilibrated by molecular dynamics (NPT at $300 \mathrm{~K}$ and $1 \mathrm{~atm}$ ) and then optimized again. To generate a mineral surface convenient for the simulation, the lattice constant $c$ of the cell was extended to $100 \AA$. Surfaces were then hydrated by a monolayer of water molecules.

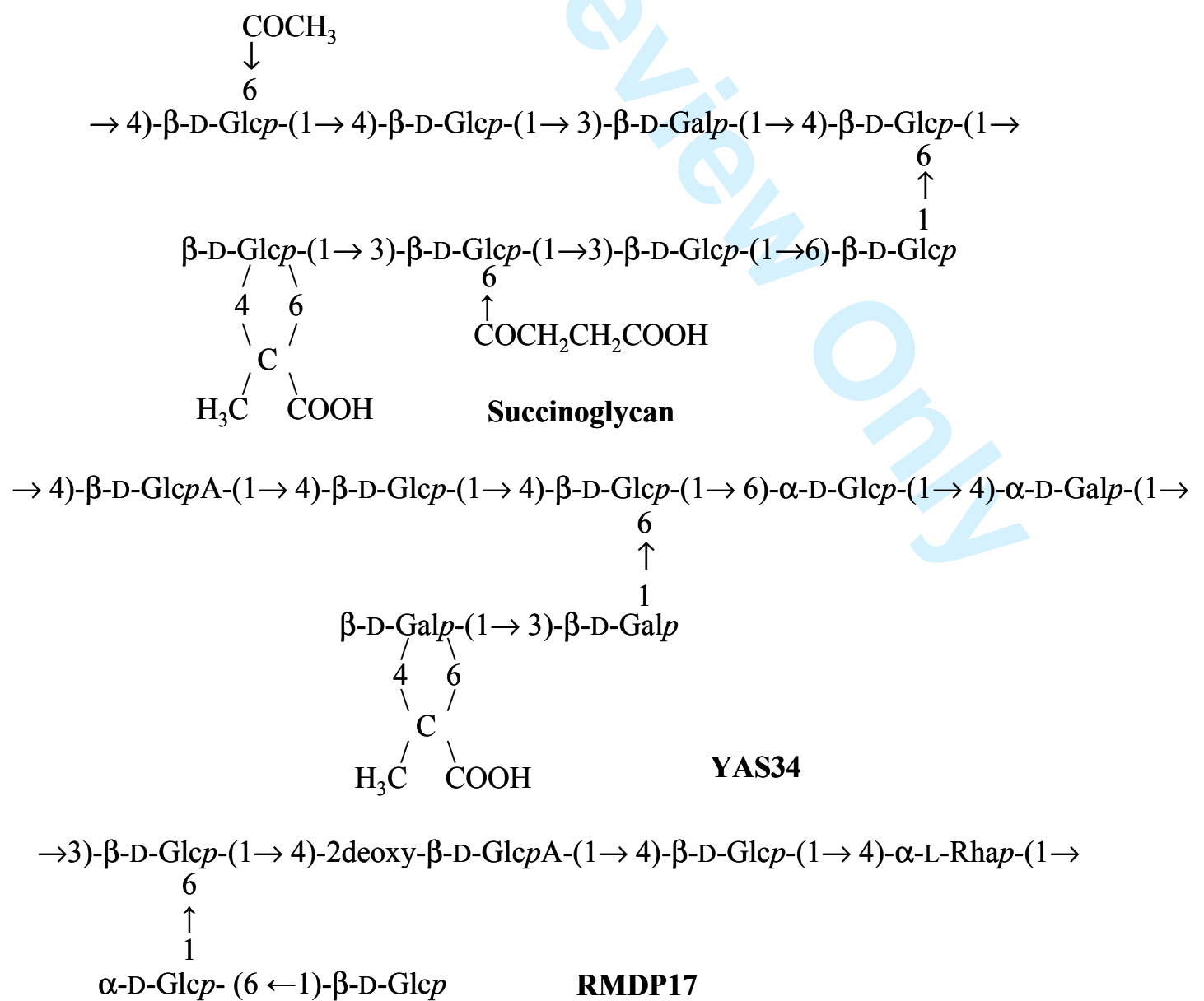




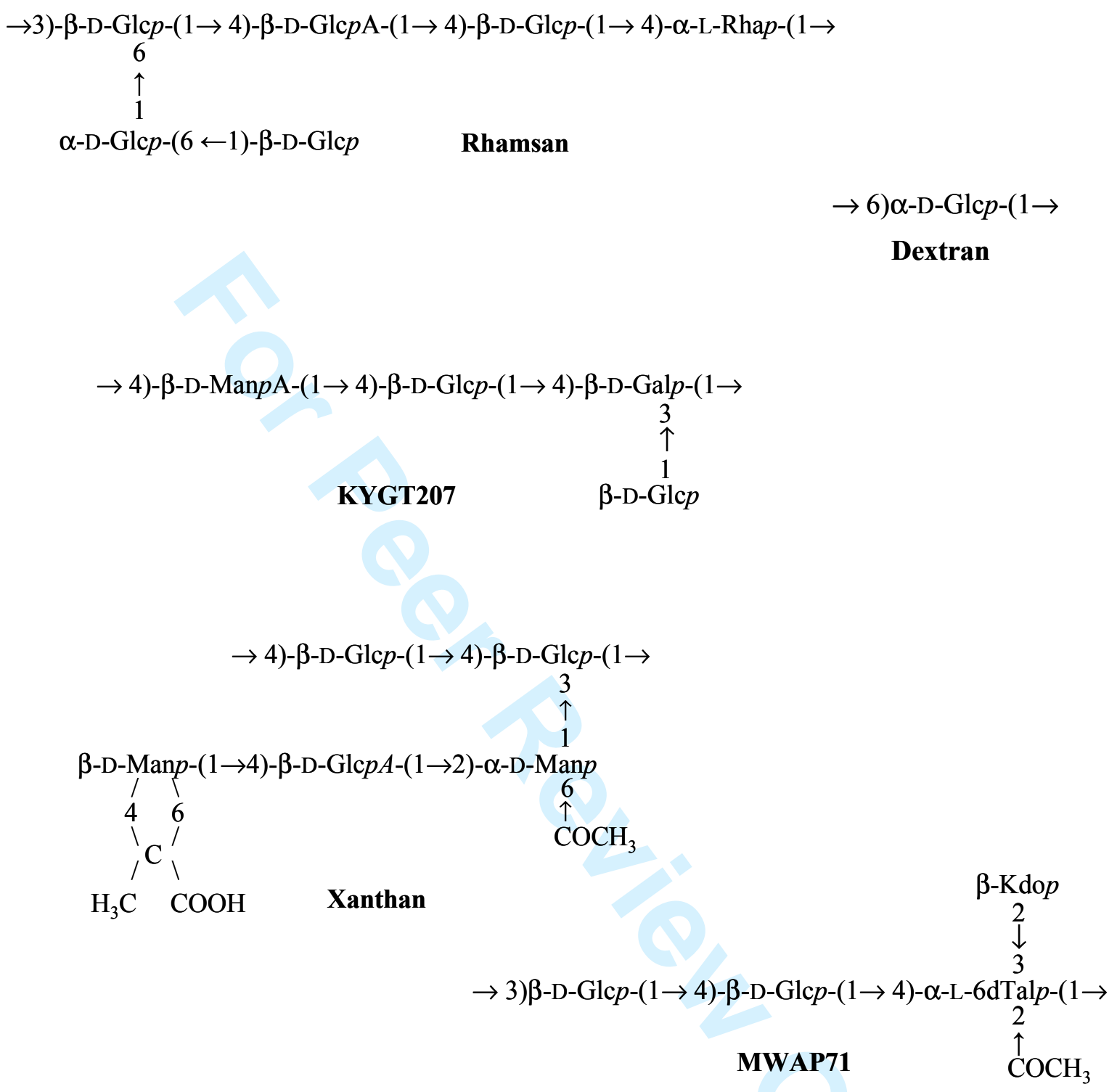

Figure 1. Chemical structures of the polysaccharides considered in this study.

\section{Organic chemicals.}

We studied the adsorption of chemical groups, monosaccharides and oligosaccharides; they are all related to the EPS indicated in Figure 1. The chemical groups considered are : methane $\left(\mathrm{CH}_{4}\right)$, ethane $\left(\mathrm{CH}_{3} \mathrm{CH}_{3}\right)$, methanol $\left(\mathrm{CH}_{3} \mathrm{OH}\right)$, ethanol $\left(\mathrm{CH}_{3} \mathrm{CH}_{2} \mathrm{OH}\right)$, 2-propanol $\left(\mathrm{CH}_{3} \mathrm{CH}_{2} \mathrm{OHCH}_{3}\right)$, methanoic acid $(\mathrm{HCOOH})$, ethanoic acid $\left(\mathrm{CH}_{3} \mathrm{COOH}\right)$, methanal $(\mathrm{HCHO})$, ethanal $\left(\mathrm{CH}_{3} \mathrm{CHO}\right)$, dimethyl ketone $\left(\mathrm{CH}_{3}(\mathrm{CO}) \mathrm{CH}_{3}\right)$, methoxymethane $\left(\mathrm{CH}_{3} \mathrm{OCH}_{3}\right)$, methyl ethanoate $\left(\mathrm{CH}_{3}(\mathrm{CO}) \mathrm{OCH}_{3}\right)$, sodium acetate $\left(\mathrm{CH}_{3} \mathrm{COO}^{-} \mathrm{Na}^{+}\right)$. The twenty monosaccharides 


\section{Modelling the adsorption.}

An organic molecule is then inserted in the simulation box above the mineral surface in a random orientation. Configurational sampling was then performed using a combination of energy minimization and molecular dynamics at elevated temperatures, typically 400 to 600 K. A typical dynamic simulation lasts 500 ps for the shortest ones, up to 2 ns for the longest ones. Once adsorbed, a $20 \AA$ slab of amorphous water molecules was added to the system. The resulting hydrated model was first minimized, equilibrated for $10 \mathrm{ps}$ and minimized again 
prior to analysis. Calculations have been repeated three times on several test cases, results were consistent.

\section{Computational details.}

The Universal force field was used, UFF[35]. This choice resulted from a compromise between good accuracy and availability of the parameters for all atom types present in the molecular models. This force field was successfully used in independent studies of organoclay species[29, 36, 37: Pospisil, 2004 \#54]. Furthermore, preliminary tests reveal that this force field correctly reproduces the particular conformational properties of carbohydrates: puckering of the pyran rings and the exo-anomeric effect. The charge equilibration method was used to calculate charges for each atom[38]. Long-range interactions were treated by the Ewald summation technique[39]. The simple point charge model (SPC) was used for the water molecules.

The minimization uses the conjugate gradient procedure with the convergence criterion of the root-mean-square of the atomic derivatives of $0.05 \mathrm{kcal} \mathrm{mol}^{-1} \AA^{-1}$.

Molecular dynamic calculations were based on the canonical NVT ensemble (constant number of particles, volume, and temperature). The equations of motion were solved using the standard Verlet algorithm[40], with a time step of $1 \mathrm{fs}$. The system is coupled to a bath at the desired temperature using Nose's algorithm[41]. During the production MD simulations, the positions of the mineral surface atoms were fixed, but all remaining system components (counter ion, organic molecule, water) were allowed to move accordingly.

\section{Properties.}

Enthalpies of adsorption.

Ten structures (snapshots) were randomly selected and minimized from the molecular dynamic trajectory. The total potential energy of a microstate may be written as:

$$
\mathrm{E}_{\text {tot }}=\mathrm{E}_{\text {clay }}+\mathrm{E}_{\text {ligand }}+\mathrm{E}_{\text {inter }}
$$

where the first three terms represent the energy of the total system, the energy of montmorillonite alone, and the energy of the ligand molecule, and consist of both valence and nonbonded components. The last term is the interaction energies between the clay and the ligand (consisting of nonbonded terms only). The enthalpy of adsorption is taken as the negative of the interaction energies of the 10 selected structures: 


$$
\Delta \mathrm{H}_{\mathrm{ads}}=-<\mathrm{E}_{\text {inter }}>
$$

We were interested by the energy change of the carbohydrate structure when it goes out of the solution to the adsorbed state : $\Delta \mathrm{E}$. Dynamic trajectories of the carbohydrate structures were thus performed, in the absence of the mineral surface.

$$
\Delta \mathrm{E}=\mathrm{E}_{\mathrm{ads}}-\mathrm{E}_{\mathrm{Free}}
$$

where $E_{a d s}$ and $E_{F r e e}$ are the energies of the adsorbed and isolated (in the absence of the mineral surface) conformations, respectively.

Surface area in contact.

The estimation of the molecular surface areas was performed with the Connolly dot algorithm,[42] with a probe radius of $1.4 \AA$.

Hydrogen bonds.

The method traditionally used to detect a hydrogen bond is geometric: two oxygen atoms are considered hydrogen bonded if the distance between the hydrogen of the donor and the oxygen acceptor is lower than $2.5 \AA$ and if the angle between the oxygen donor, the hydrogen donor and the oxygen acceptor larger than $90^{\circ}$.

\section{Results and discussion.}

A hierarchical approach was chosen to reveal the adsorption behavior of polysaccharides onto the basal surface of the clay mineral. Adsorption of chemical groups was examined first, followed by adsorption of monosaccharides. Finally the adsorption of oligosaccharides was considered. Idealized chemical structures of the EPS are given in Figure 1; it was experimentally shown that all of them do adsorb on mineral surfaces. Predicted quantities are the energies associated with the binding and also the geometry of the complexes.

During the dynamics trajectory, the total energy decreases when the saccharide adsorbs onto the surface of the clay mineral, suggesting that the whole modeled system reaches a more stable state. Consequently, the positive values of $\Delta \mathrm{H}_{\mathrm{ads}}$ (or the negative values of $\mathrm{E}_{\text {int }}$ ) indicate that the adsorption is a favorable process. 


\section{Adsorption of functional groups.}

During the dynamics simulation, the chemical groups explore several adsorption sites of similar energy. Table 1 gives their average interaction energies with the mineral surface. The counter ion has no noticeable effect on the interaction of hydrophobic groups (Methyl and Ethyl) with the clay surface. In contrast, it strongly participates to the interaction with polar groups. Alcohol and carboxyl groups form Hydrogen Bonds with the oxygen atoms of the mineral surface; electrostatic interactions (ionic like) also occur, between the oxygen atoms of the organic molecule and the counter ion.

The interaction of very small molecular fragments of saccharides with the mineral surface can be considered unperturbed by structural effects, the interaction is thus optimal and the estimated values of the enthalpies of adsorption give the orders of magnitude of the energies involved upon adsorption. The interaction of the different functions on the mineral surface is globally weak; the energy of a hydrogen bond $\mathrm{O}-\mathrm{H} . . . \mathrm{O}$ and a hydrophobic interaction are typically in the range 4 to $5 \mathrm{kcal} / \mathrm{mol}$ and 1 to $3 \mathrm{kcal} / \mathrm{mol}$, respectively. Our results are in agreement with these values, suggesting that the force field correctly reproduces the basic interaction energies.

\begin{tabular}{|c|c|c|c|c|c|c|c|c|}
\hline & \multicolumn{9}{|c|}{ Without counter-ion } & \multicolumn{4}{c|}{ With counter-ion } \\
\hline Group & $\mathrm{E}_{\mathrm{c}}$ & $\mathrm{E}_{\mathrm{vw}}$ & $\mathrm{E}_{\text {tot }}$ & $\mathrm{S}_{\text {int }}$ & $\mathrm{E}_{\mathrm{c}}$ & $\mathrm{E}_{\mathrm{vw}}$ & $\mathrm{E}_{\text {tot }}$ & $\mathrm{S}_{\text {int }}$ \\
\hline $\mathrm{CH}_{4}$ & 0 & -6 & -6 & 18 & -1 & -6 & -7 & 18 \\
\hline $\mathrm{CH}_{3} \mathrm{OH}$ & -3 & -7 & -10 & 22 & -28 & -3 & -31 & 24 \\
\hline $\mathrm{HCHO}$ & -5 & -6 & -11 & 16 & -21 & -4 & -25 & 23 \\
\hline $\mathrm{HCOOH}$ & -1 & -7 & -8 & 22 & -17 & -5 & -22 & 23 \\
\hline $\mathrm{CH}_{3} \mathrm{CH}_{3}$ & 0 & -9 & -9 & 25 & -4 & -8 & -12 & 25 \\
\hline $\mathrm{CH}_{3} \mathrm{CH}_{2} \mathrm{OH}$ & -2 & -11 & -13 & 27 & -30 & -5 & -35 & 28 \\
\hline $\mathrm{CH}_{3} \mathrm{CHO}$ & -5 & -10 & -15 & 22 & -23 & -8 & -31 & 28 \\
\hline $\mathrm{CH}_{3} \mathrm{COOH}$ & -1 & -11 & -12 & 30 & -20 & -8 & -28 & 30 \\
\hline $\mathrm{CH}_{3} \mathrm{OCH}$ & 0 & -11 & -11 & 34 & -31 & -6 & -37 & 32 \\
\hline $\mathrm{CH}_{3} \mathrm{CHOHCH}_{3}$ & -2 & -13 & -15 & 30 & -29 & -8 & -37 & 30 \\
\hline $\mathrm{CH}_{3}(\mathrm{CO}) \mathrm{CH}_{3}$ & -2 & -13 & -15 & 35 & -25 & -10 & -35 & 34 \\
\hline $\mathrm{CH}_{3}(\mathrm{CO}) \mathrm{OCH}_{3}$ & -2 & -14 & -16 & 36 & -29 & -12 & -41 & 41 \\
\hline
\end{tabular}

Table 1. Energies $(\mathrm{kcal} / \mathrm{mol})$ and interacting areas $\left(\AA^{2}\right)$ of several chemical moieties adsorbed onto the mineral surface. $E_{\text {tot }}$ : total energy, $E_{c}$ and $E_{v w}$ are its coulomb and Van der Waals components. Standard deviations on energies ranged between 1 to $3 \mathrm{kcal} / \mathrm{mol}$ and those on surfaces ranged between 1 to $5 \AA^{2}$. 


\section{Monosaccharides and oligosaccharides}

\begin{tabular}{|c|c|c|c|c|c|c|c|c|}
\hline & & & $\mathrm{Wi}$ & $\mathrm{tcou}$ & ion & & count & \\
\hline Monomer & Substituents & $\mathrm{S}_{\mathrm{tot}}$ & $\mathrm{E}_{\text {int }}$ & $\mathrm{S}_{\text {int }}$ & $\Delta \mathrm{E}$ & $\mathrm{E}_{\mathrm{int}}$ & $\mathrm{S}_{\text {int }}$ & $\Delta \mathrm{E}$ \\
\hline$\beta$-D-Glc $p$ & Me1 & 192 & -31 & 69 & 4 & -99 & 81 & 13 \\
\hline$\beta$-D-Glc $p$ & $\begin{array}{l}\text { Me1, } \\
\text { Me3 }\end{array}$ & 205 & -35 & 84 & 2 & -107 & 93 & 12 \\
\hline$\beta-\mathrm{D}-\mathrm{Glc} p$ & $\begin{array}{l}\text { Me1, } \\
\text { Me4 }\end{array}$ & 203 & -34 & 83 & 7 & -104 & 85 & 15 \\
\hline$\beta$-D-Glc $p$ & $\begin{array}{l}\text { Me1, Me3, } \\
\text { Me4 }\end{array}$ & 222 & -39 & 87 & 6 & -111 & 102 & 15 \\
\hline$\beta$-D-Glc $p$ & $\begin{array}{l}\text { Me1, Me4, } \\
\text { Me6 }\end{array}$ & 220 & -43 & 93 & 8 & -123 & 98 & 19 \\
\hline$\beta$-D-Glc $p$ & $\begin{array}{l}\text { Me1, } \\
\text { Me6 }\end{array}$ & 209 & -38 & 83 & -3 & -113 & 92 & 12 \\
\hline$\alpha$-D-Glc $p$ & $\begin{array}{l}\text { Me1, } \\
\text { Me6 }\end{array}$ & 209 & -33 & 76 & 6 & -120 & 87 & 17 \\
\hline$\beta$-D-Glc $p$ & $\begin{array}{l}\mathrm{Me} 1, \mathrm{Me} 4, \\
6-\mathrm{COCH}_{3}\end{array}$ & 253 & -43 & 94 & 1 & -110 & 104 & 10 \\
\hline$\beta$-D-Glc $p$ & $\begin{array}{l}\mathrm{Me} 1, \mathrm{Me} 3, \\
6-\mathrm{COCH}_{2} \\
\mathrm{CH}_{2} \mathrm{COOH}\end{array}$ & 307 & -48 & 116 & 13 & -146 & 129 & 26 \\
\hline$\beta$-D-Glc $p$ A & $\begin{array}{l}\text { Me1, } \\
\text { Me4 }\end{array}$ & 208 & -34 & 82 & -3 & -88 & 82 & 6 \\
\hline 2 deoxy- $\beta$-D-Glc $p$ A & $\begin{array}{l}\text { Me1, } \\
\text { Me4 }\end{array}$ & 199 & -36 & 83 & -2 & -95 & 93 & 19 \\
\hline$\beta$-D-Glc $p$ & $\begin{array}{l}\text { Me1, } \\
\text { 4-6pyruvate }\end{array}$ & 239 & -35 & 86 & 0 & -84 & 84 & 4 \\
\hline$\beta-\mathrm{D}-\mathrm{Gal} p$ & $\begin{array}{l}\text { Me } 1 \\
\text { Me } 3\end{array}$ & 209 & -35 & 79 & 3 & -94 & 81 & 7 \\
\hline$\alpha-\mathrm{D}-\mathrm{Gal} p$ & $\begin{array}{l}\text { Me } 1 \\
\text { Me } 4\end{array}$ & 202 & -32 & 68 & -3 & -90 & 77 & 12 \\
\hline$\beta$-D-Galp & $\begin{array}{l}\text { Me 1, } \\
\text { 4-6pyruvate }\end{array}$ & 235 & -31 & 81 & 8 & -97 & 90 & 15 \\
\hline$\alpha$-D-Man $p$ & $\begin{array}{l}\text { Me 1, Me 2, } \\
6 \mathrm{COCH}_{3}\end{array}$ & 241 & -36 & 82 & 5 & -95 & 96 & 17 \\
\hline$\beta$-D-Man $p$ & $\begin{array}{l}\text { Me } 1, \\
\text { 4-6pyruvate }\end{array}$ & 235 & -31 & 81 & -1 & -92 & 91 & 2 \\
\hline$\alpha$-L-Rha $p$ & $\begin{array}{l}\text { Me 1, } \\
\text { Me } 4\end{array}$ & 193 & -25 & 58 & 1 & -53 & 62 & 3 \\
\hline$\beta-\mathrm{Kdo} p$ & $\mathrm{Me} 2$ & 225 & -30 & 72 & 4 & -106 & 77 & 14 \\
\hline$\alpha$-L-6dTal $p$ & $\begin{array}{l}\mathrm{Me} 1, \mathrm{Me} 3, \\
\mathrm{Me} 4, \\
2 \mathrm{COCH}_{3}\end{array}$ & 242 & -24 & 58 & 4 & -92 & 74 & 14 \\
\hline
\end{tabular}

Note: Kdo is the 3-deoxy-D-Manno-oct-2-ulosonic acid.

Table 2. Energetic and geometric characteristics of selected monomers of carbohydrates adsorbed onto the clay mineral surface in the presence or absence of counter-ion. Energy of interaction $\left(\mathrm{E}_{\text {int }}\right.$ in $\left.\mathrm{kcal} / \mathrm{mol}\right)$; difference in energy between the free state and the adsorbed state $(\Delta \mathrm{E}$ in $\mathrm{kcal} / \mathrm{mol})$. Total solvent exposed surface $\left(\mathrm{S}_{\text {tot }}\right.$ in $\left.\AA^{2}\right)$, surface in interaction $\left(\mathrm{S}_{\text {int }}\right.$ in 


\begin{abstract}
$\AA^{2}$ ). Standard deviations on energies ranged between 2 to $8 \mathrm{kcal} / \mathrm{mol}$ and those on surfaces ranged between 1 to $14 \AA^{2}$.
\end{abstract}

Dynamical behavior of mono- and oligosaccharides differ from that of functional groups. They touched the mineral surface and explored several orientations prior to converging to their preferred adsorption geometry. This suggests that the potential energy surface has many energy minima. The energy decreases gradually with time during the course of the simulation and only the final parts of the trajectories were considered (when the total energy is stabilized to its minimal value), in order to estimate the interaction energies. On average, only 30 to $40 \%$ of the total accessible surface of monosacharides is in direct contact with the mineral surface; this value is remarkably unchanged for the oligomeric fragments.

\title{
Monosaccharides.
}

All the monomers considered in this study are indicated in Table 2 with the structural and energy details of their adsorption on the mineral surface.

The adsorption enthalpy strongly depends on several factors, including the number of pendant groups, their nature, position and orientation with respect to the pyran ring. Figure 2 compares the preferred geometry of interaction of two glucoses 1,6 dimethylated ( $\alpha$ and $\beta$ ). Inverting the configuration on the anomeric carbon atom changed the adsorption features of the monosaccharide on the mineral surface.

Here again, the counter ion favors the adsorption of the monosaccharides. The average interaction energy was $-30 \mathrm{kcal} / \mathrm{mol}$ in the absence of counter ions; it reached $-106 \mathrm{kcal} / \mathrm{mol}$ in their presence. Inspection of the models reveals the strong similarity of the binding of monosaccharides with that of the functional groups: hydrogen bonds and ionic interactions. Hydrophobic interactions seem to play a particular role. Methyl groups were in direct contact with the surface and the monosaccharide-surface interaction was stronger when more Omethoxy groups were present (see Table 2). 

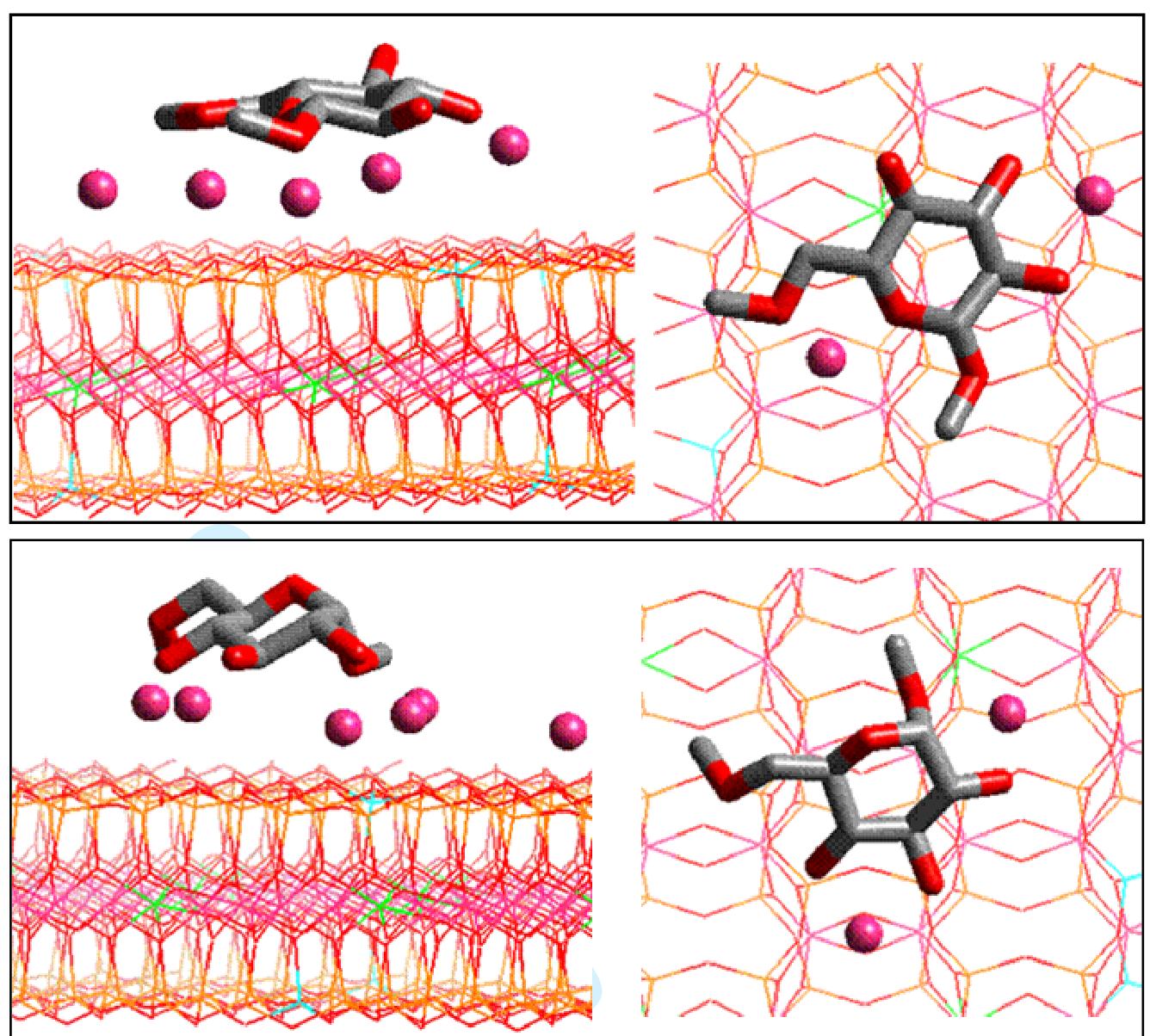

Figure 2. Equilibrium adsorbed geometry of $\beta$-glucose (top) and $\alpha$-glucose (bottom) methylated at positions 1 and 6. Left side views, right front views. Hydrogen atoms are omitted for clarity.

The group contribution method clearly overestimated the interaction energies. For example, group method predicts an energy of interaction of about $-200 \mathrm{kcal} / \mathrm{mol}$ for a simple disubstituted Glucose molecule. The energies really involved with the adsorption of such molecules are much lower than this expected value, they ranged between $-104 \mathrm{kcal} / \mathrm{mol}$ and $120 \mathrm{kcal} / \mathrm{mol}$. This is not surprising as the group contribution assumes an optimal interaction whereas, in reality, the adsorption is far from perfect. In addition, structural effects are neglected in the group method; it cannot discriminate between different stereo isomers. The changes in the conformational energies $(\Delta \mathrm{E})$ were minimal for the monosaccharides. They are made of a pyran ring which adopts a dominant chair conformation, except for very rare cases. The chair geometry remained when the monosaccharide is adsorbed, by contrast, side chains showed flexibility. 


\section{Oligomers : repeat units of EPS.}

Given the results of the previous section, simulations on the oligomeric structures of carbohydrates were systematically performed in the presence of the counter ions. Their energies of interaction with the clay surface are given in Table 3, the geometrical aspects of the adsorption are given in Table 4.

\begin{tabular}{|c|c|c|c|c|}
\hline & $\Delta \mathrm{H}_{\text {Ads }}$ & $\mathrm{E}_{\text {adsorb }}$ & $\mathrm{E}_{\text {Free }}$ & RMSD \\
\hline dextran & 351 & 725 & 646 & 0,0234 \\
\hline KYGT207 & 240 & 486 & 442 & 0,0304 \\
\hline MWAP71 & 151 & 421 & 394 & 0,0145 \\
\hline rhamsan & 333 & 686 & 615 & 0,0362 \\
\hline RMDP17 & 316 & 603 & 509 & 0,0465 \\
\hline succinoglycan & 564 & 950 & 785 & 0,0245 \\
\hline xanthan & 268 & 592 & 541 & 0,0230 \\
\hline YAS34 & 445 & 958 & 841 & 0,0153 \\
\hline
\end{tabular}

Table 3. Selected characteristics of the repeat units of EPS. $\Delta \mathrm{H}_{\mathrm{Ads}}$ : enthalpy of adsorption of the oligomer on the mineral surface, $E_{\text {adsorb }}$ : average energy of the adsorbed conformation, $E_{\text {Free }}$ : average energy of the equilibrium conformation in the absence of the surface, RMSD root mean square deviation per atom between the free and the adsorbed conformations. Energies are given in $\mathrm{kcal} / \mathrm{mol}$.

\begin{tabular}{|c|c|c|c|c|}
\hline & $\mathrm{S}_{\text {totcompl }}$ & $\mathrm{S}_{\text {Free }}$ & $\mathrm{S}_{\text {interact }}$ & $\mathrm{Mw}$ \\
\hline dextran & 806 & 743 & 345 & 1018 \\
\hline KYGT207 & 550 & 531 & 239 & 708 \\
\hline MWAP71 & 599 & 595 & 202 & 778 \\
\hline rhamsan & 796 & 737 & 340 & 1016 \\
\hline RMDP17 & 802 & 745 & 314 & 1000 \\
\hline succinoglycan & 1244 & 1071 & 549 & 1554 \\
\hline xanthan & 773 & 735 & 304 & 982 \\
\hline YAS34 & 942 & 967 & 386 & 1264 \\
\hline
\end{tabular}


Table 4. Geometric characteristics (in $\AA^{2}$ ) of the adsorption of the repeat units of EPS. $\mathrm{S}_{\text {totcompl }}$ : solvent accessible surface of the adsorbed conformation, $\mathrm{S}_{\text {Free }}$ solvent accessible surface of the free conformation, $\mathrm{S}_{\text {interact }}$ area in interaction. Molecular masses of the different fragments of EPS are also indicated $(\mathrm{Mw})$.

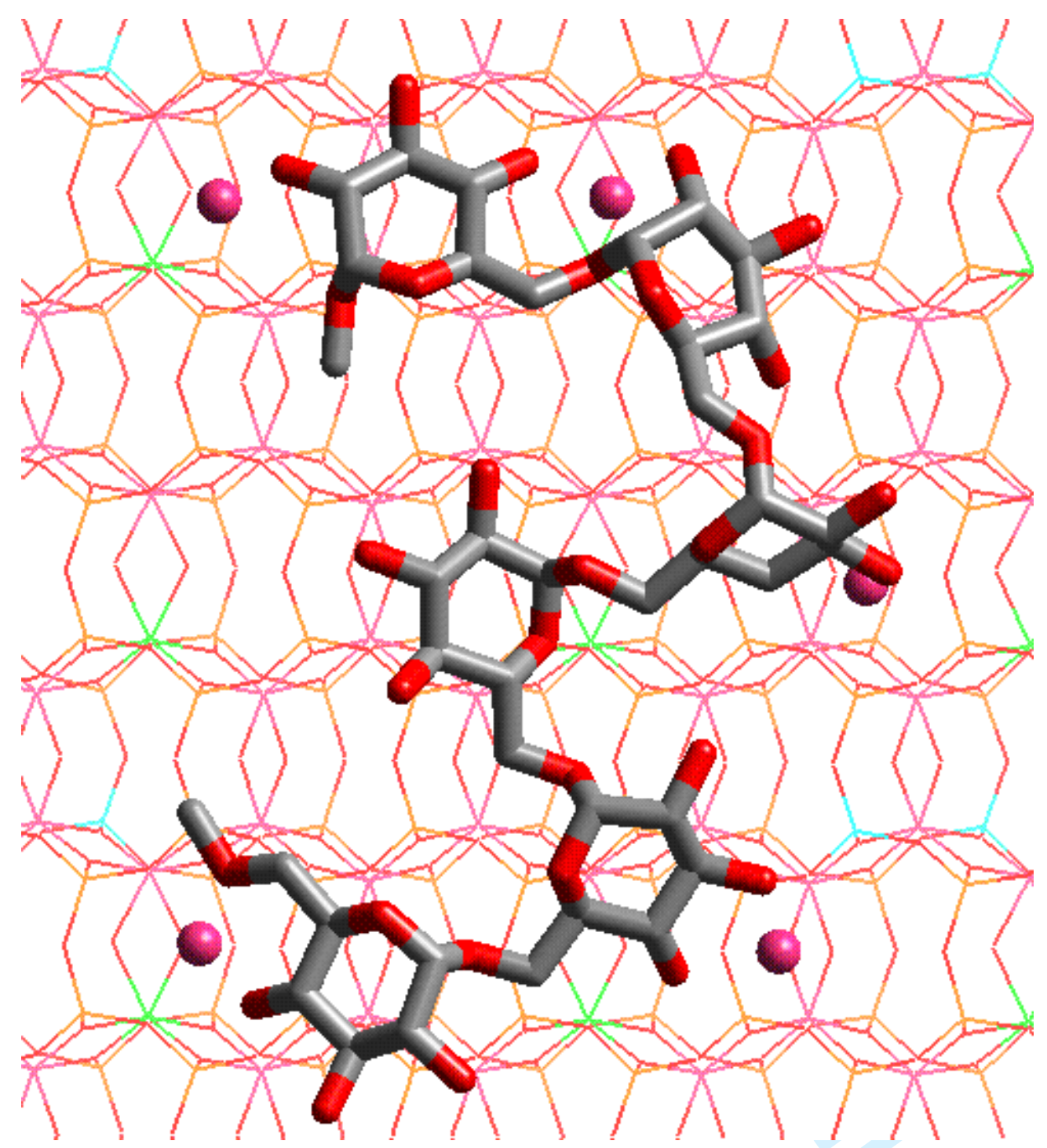

Figure 3. Equilibrium adsorbed geometry of the dextran fragment. Hydrogen atoms and water molecules are omitted for clarity.

Inspecting the molecular models shows that the monomers in the adsorbed conformational state do not systematically adopt the unperturbed orientation revealed in the preceding section. To illustrate this, Figure 3 gives the adsorbed fragment of dextran ; among its six $\alpha$ Glc residues; four of them adsorb in an identical geometry already observed in the study of free monosaccharides; by contrast, the remaining two $\alpha$-Glc behave differently. Chemical 
connectivity induces geometrical constraints that limit the number of accessible orientations of the constituent monosaccharides with respect to the mineral surface. However, the potential energy surface contains a huge amount of energy minima; monomer units that are part of a polymer simply explore secondary potential wells.
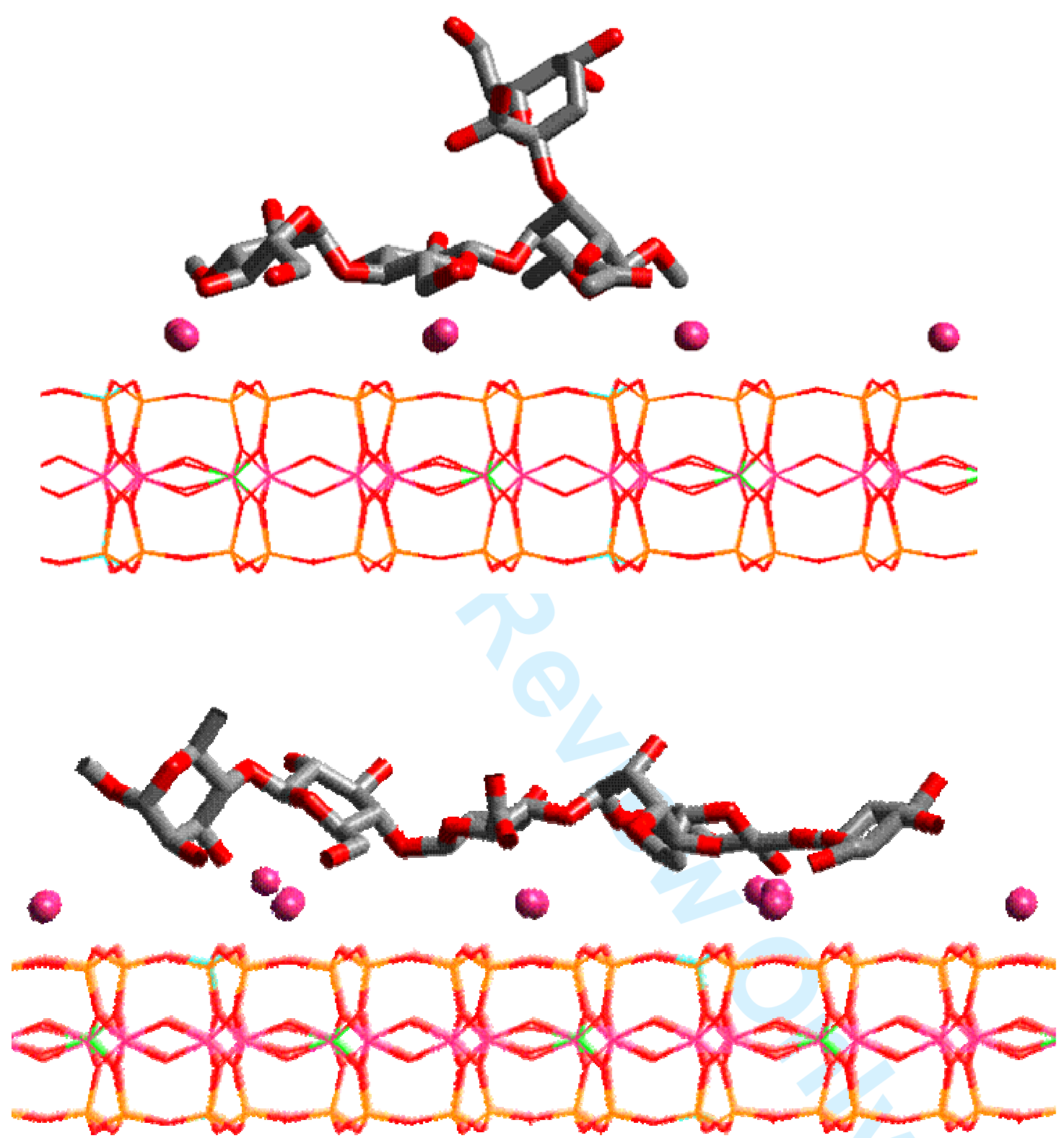

Figure 4. Equilibrium adsorbed geometry of the MWAP71 (top) and the RMDP17 (bottom). Hydrogen atoms and water molecules are omitted for clarity.

The presence of the surface systematically induced an increase of the internal energy of the EPS fragments. The conformation was thus less stable when adsorbed than when isolated; the difference reaches $20 \%$ in the case of RMDP17 and succinoglycan. The presence of the surface also induced an increase of the total accessible surface of the organic molecule. The 


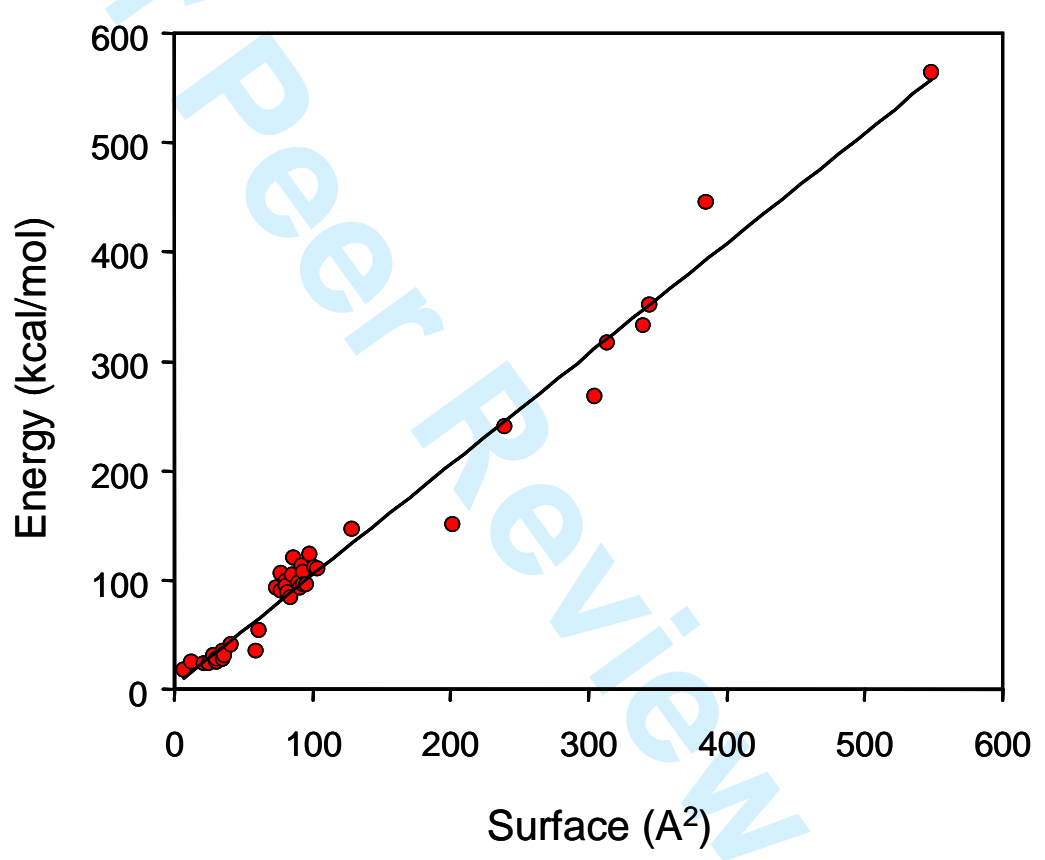

Figure 5. Energy of adsorption as a function of the interacting area.

Figure 5 gives the correlation between the estimated enthalpies of adsorption and the effective interacting area. The linear relationship suggests that the real area in interaction is the critical factor on which depends the adsorption of the tested EPS. Structural factors play a role in the deviation with respect to the master line.

All these results strongly suggest that the oligosaccharide have one (or several) unperturbed solution conformation and another conformation when it is adsorbed on a surface. In contrast with the rigid monosaccharides, the glycosidic bonds linking the monomers together provide conformational freedom in an oligomeric structure. Such flexibility allows the oligomer to 
change its shape upon interaction with the mineral surface. In other words, the more flexible the structure, the stronger the interaction. It is thus obvious that the deformation ability (to optimize the interaction) of linear polymers is larger than that of branched polymers for which the side chains induce a steric hindrance that restrict the flexibility of the whole molecule. Accordingly, the fragment of MWAP71 (Figure 4) is rigid; its conformational adaptation is restricted to 3 glycosidic bonds and the Kdo pendant group is not in interaction with the surface. In contrast the large flexibility of RMDP17 (5 glycosidic bonds) allows all its monomer units being in contact with the surface.

\section{Comparison with the experiments.}

The accuracy of the models could be assessed by comparing the predicted data to the experimental data. Our results revealed the strong participation of the counter ion in the stability of the complex. They considerably increased the interaction energy between the EPS segment and the mineral surface. The crucial role of electrostatic (ionic) interactions through counter ions is also revealed by many experiments[22, 43-45]. Complexes were also stabilized by hydrogen bonds and hydrophobic interactions. Experimental data show that adsorption of ethyl(hydroxyethyl)cellulose on talc is destabilized by urea, which is an hydrogen bond breaker[12]. Finally, the importance of the hydrophobic interactions is counter intuitive; it is however consistent with NMR results which indicate that aliphatic chains are in direct contact with montmorillonite[46]. Our models also showed that the oligosaccharides undergo conformational changes between the solution states and the adsorbed state. Quartz crystal microbalance with dissipation monitoring (QCM-D) experiments reveal that the adsorbed conformation of dextran on alumina differs from that in solution[47].

Experiments are also performed to establish the structure-property relationships. The ability of several EPS to flocculate a colloidal suspension of clay particles is compared[26]. Experiments measure the average size of the flocs which indirectly reflects the efficiency of the EPS to bridge different mineral particles. Such measurements thus give an indication of the affinity of the EPS with the mineral surface. An interaction efficiency coefficient (IEC) was defined in order to allow the comparison between the experimental and modeling approaches. The IEC corresponded to the enthalpy of adsorption, normalized by the effective interaction area. Experimental floc size in the presence of succinoglycan $(335 \mu \mathrm{m})$ is much larger than that of xanthan $(158 \mu \mathrm{m})$; even though the molar mass of the xanthan sample is twice the mass of succinoglycan. In qualitative agreement with the experiments, IEC of succinoglycan $\left(1027 \mathrm{cal} / \mathrm{mol} \AA^{2}\right)$ was estimated larger than that of xanthan $\left(882 \mathrm{cal} / \mathrm{mol} \AA^{2}\right)$. 


\section{Conclusion.}

Atomic level molecular simulations were applied to investigate the interaction features of model molecules mimicking bacterial exopolysaccharides (in their neutral forms) with the basal surface of Na-montmorillonite surface. The study has been performed using Cerius 2 and material studio modeling programs.

It was found that hydrogen bonds, electrostatic and hydrophobic interactions are present in the model systems and provide a significant effect on the adsorption strength of EPS fragments on the mineral surface. The adsorption of monosaccharides was dependant on the nature of the monomer and its side chains. The six-membered ring stayed in its preferred geometry when adsorbed. In contrast, oligosaccharides changed their shape upon adsorption. It was found that the enthalpies of adsorption linearly increase with increasing the interacting surface area, suggesting that the key factor determining the adsorption is the ability of the EPS to unfold in order to maximize its surface in contact. The most flexible structures were the most favorable candidates for adsorption. The present modelling was able to predict a complex physical adsorption phenomenon in agreement with the experimental results.

\section{References}

[1] S. S. Ray, M. Okamoto. Polymer/layered silicate nanocomposites: a review from preparation to processing. Progress in Polymer Science. 28,1539 (2003). 
[2] M. Alexandre, P. Dubois. Polymer-layered silicate nanocomposites: preparation, properties and uses of a new class of materials. Materials Science \& Engineering, R: Reports. R28, 1 (2000).

[3] J. M. Dorioz, M. Robert, C. Chenu. The role of roots, fungi and bacteria on clay particle organization. An experimental approach. Geoderma. 56,179 (1993).

[4] C. Chenu. Clay- or sand-polysaccharide associations as models for the interface between microorganisms and soil: water related properties and microstructure. Geoderma. 56, 143 (1993).

[5] E. B. Roberson, M. K. Firestone. Relationship between desiccation and exopolysaccharide production in a soil Pseudomonas sp. Applied and Environmental Microbiology. 58, 1284 (1992).

[6] Y. Alami, W. Achouak, C. Marol, T. Heulin. Rhizosphere soil aggregation and plant growth promotion of sunflowers by an exopolysaccharide-producing Rhizobium sp. strain isolated from sunflower roots. Applied and Environmental Microbiology. 66,3393 (2000). [7] M. Ashraf, S. Hasnain, O. Berge, T. Mahmood. Inoculating wheat seedlings with exopolysaccharide-producing bacteria restricts sodium uptake and stimulates plant growth under salt stress. Biology and Fertility of Soils. 40,157 (2004).

[8] P. G. Hartel, M. Alexander. Role of extracellular polysaccharide production and clays in the desiccation tolerance of cowpea bradyrhizobia. Soil Science Society of America Journal. 50, 1193 (1986).

[9] C. Chenu, Y. Le Bissonnais, D. Arrouays. Organic matter influence on clay wettability and soil aggregate stability. Soil Science Society of America Journal. 64, 1479 (2000).

[10] D. Cosentino, C. Chenu, Y. Le Bissonnais. Aggregate stability and microbial community dynamics under drying-wetting cycles in a silt loam soil. Soil Biology \& Biochemistry. 38,2053 (2006).

[11] C. Chenu, J. Guerif, A. M. Jaunet. Polymer bridging: A mechanism of clay and soil structure stabilization by polysaccharides. Transactions, World Congress of Soil Science, 15th, Acapulco, Mexico, July 10-16, 1994. 3a,403 (1994).

[12] S. Simon, D. Le Cerf, L. Picton, G. Muller. Adsorption of cellulose derivatives onto montmorillonite: a SEC-MALLS study of molar masses influence. Colloids and Surfaces, A: Physicochemical and Engineering Aspects. 203, 77 (2002).

[13] H.-M. Park, M. Misra, L. T. Drzal, A. K. Mohanty. \"Green\" Nanocomposites from Cellulose Acetate Bioplastic and Clay: Effect of Eco-Friendly Triethyl Citrate Plasticizer. Biomacromolecules. 5,2281 (2004). 
[14] H.-M. Park, A. K. Mohanty, L. T. Drzal, E. Lee, D. F. Mielewski, M. Misra. Effect of Sequential Mixing and Compounding Conditions on Cellulose Acetate/Layered Silicate Nanocomposites. Journal of Polymers and the Environment. 14,27 (2006).

[15] S. F. Wang, L. Shen, Y. J. Tong, L. Chen, I. Y. Phang, P. Q. Lim, T. X. Liu. Biopolymer chitosan/montmorillonite nanocomposites: Preparation and characterization. Polymer Degradation and Stability. 90,123 (2005).

[16] M. Darder, M. Colilla, E. Ruiz-Hitzky. Biopolymer-Clay Nanocomposites Based on Chitosan Intercalated in Montmorillonite. Chemistry of Materials. 15,3774 (2003).

[17] M. Darder, M. Colilla, E. Ruiz-Hitzky. Chitosan-clay nanocomposites: application as electrochemical sensors. Applied Clay Science. 28,199 (2005).

[18] J. Labille, F. Thomas, I. Bihannic, C. Santaella. Destabilization of montmorillonite suspensions by Ca2+ and succinoglycan. Clay Minerals. 38,173 (2003).

[19] N. Amellal, G. Burtin, F. Bartoli, T. Heulin. Colonization of wheat roots by an exopolysaccharide-producing Pantoea agglomerans strain and its effect on rhizosphere soil aggregation. Applied and Environmental Microbiology. 64,3740 (1998).

[20] C. Chenu, J. Guerif. Mechanical strength of clay minerals as influenced by an adsorbed polysaccharide. Soil Science Society of America Journal. 55,1076 (1991).

[21] C. Chenu. Influence of a fungal polysaccharide, scleroglucan, on clay microstructures. Soil Biology \& Biochemistry. 21,299 (1989).

[22] K. M. Dontsova, J. M. Bigham. Anionic polysaccharide sorption by clay minerals. Soil Science Society of America Journal. 69, 1026 (2005).

[23] M. He, Y. Horikawa. Partial deflocculation of mutual flocs of allophane and halloysite by xanthan and chitosan and relevance to particle arrangement in the flocs. Soil Science and Plant Nutrition (Tokyo). 46,81 (2000).

[24] S. M. Rao, A. Sridharan, M. R. Shenoy. Influence of starch polysaccharide on the remolded properties of two Indian clay samples. Canadian Geotechnical Journal. 30,550 (1993).

[25] A. Olness, C. E. Clapp. Occurrence of collapsed and expanded crystals in montmorillonite-dextran complexes. Clays and Clay Minerals, Proceedings of the Conference. 21,289 (1973).

[26] J. Labille, F. Thomas, M. Milas, C. Vanhaverbeke. Flocculation of colloidal clay by bacterial polysaccharides: effect of macromolecule charge and structure. Journal of Colloid and Interface Science. 284, 149 (2005). 
[27] S. I. Tsipursky, V. A. Drits. The distribution of octahedral cations in the 2:1 layers of dioctahedral smectites studied by oblique-texture electron diffraction. Clay Minerals. 19,177 (1984).

[28] P. Capkova, M. Pospisil, M. Valaskova, D. Merinska, M. Trchova, Z. Sedlakova, Z. Weiss, J. Simonik. Structure of montmorillonite cointercalated with stearic acid and octadecylamine: Modeling, diffraction, IR spectroscopy. Journal of Colloid and Interface Science. 300,264 (2006).

[29] A. Gaudel-Siri, P. Brocorens, D. Siri, F. Gardebien, J.-L. Bredas, R. Lazzaroni. Molecular Dynamics Study of e-Caprolactone Intercalated in Wyoming Sodium Montmorillonite. Langmuir. 19, 8287 (2003).

[30] P. Capkova, P. Maly, M. Pospisil, Z. Klika, H. Weissmannova, Z. Weiss. Effect of surface and interlayer structure on the fluorescence of rhodamine B-montmorillonite: modeling and experiment. Journal of Colloid and Interface Science. 277, 128 (2004). [31] M. Fermeglia, M. Ferrone, S. Pricl. Computer simulation of nylon-6/organoclay nanocomposites: prediction of the binding energy. Fluid Phase Equilibria. 212,315 (2003). [32] P. Capkova, J. V. Burda, Z. Weiss, H. Schenk. Modeling of aniline-vermiculite and tetramethylammonium-vermiculite; test of force fields. Journal of Molecular Modeling. 5,8 (1999).

[33] S. Perez, M. Kouwijzer, K. Mazeau, S. B. Engelsen. Modeling polysaccharides: present status and challenges. Journal of Molecular Graphics. 14,307 (1996).

[34] C. Vanhaverbeke, A. Heyraud, K. Mazeau. Conformational analysis of the exopolysaccharide from Burkholderia caribensis strain MWAP71: Impact on the interaction with soils. Biopolymers. 69,480 (2003).

[35] A. K. Rappe, C. J. Casewit, K. S. Colwell, W. A. Goddard, III, W. M. Skiff. UFF, a full periodic table force field for molecular mechanics and molecular dynamics simulations. Journal of the American Chemical Society. 114,10024 (1992).

[36] R. Toth, A. Coslanich, M. Ferrone, M. Fermeglia, S. Pricl, S. Miertus, E. Chiellini. Computer simulation of polypropylene/organoclay nanocomposites: characterization of atomic scale structure and prediction of binding energy. Polymer. 45,8075 (2004).

[37] F. Gardebien, J.-L. Bredas, R. Lazzaroni. Molecular dynamics simulations of nanocomposites based on poly(e-caprolactone) grafted on montmorillonite clay. Journal of Physical Chemistry B. 109, 12287 (2005).

[38] A. K. Rappe, W. A. Goddard, III. Charge equilibration for molecular dynamics simulations. Journal of Physical Chemistry. 95,3358 (1991). 
[39] H. Q. Ding, N. Karasawa, W. A. Goddard, III. Atomic level simulations on a million particles: the cell-multipole method for Coulomb and London nonbond interactions. Journal of Chemical Physics. 97,4309 (1992).

[40] L. Verlet. Computer \"experiments\" on classical fluids. I. Thermodynamical properties of Lennard-Jones molecules. Physical Review. 159,98 (1967).

[41] D. J. Evans, B. L. Holian. The Nose-Hoover thermostat. Journal of Chemical Physics. 83,4069 (1985).

[42] M. L. Connolly. Computation of molecular volume. Journal of the American Chemical Society. 107, 1118 (1985).

[43] L. G. Fuller, T. B. Goh, D. W. Oscarson, C. G. Biliaderis. Flocculation and coagulation of Ca- and Mg-saturated montmorillonite in the presence of a neutral polysaccharide. Clays and Clay Minerals. 43,533 (1995).

[44] Y. M. Kanaani, A. Adin, C. Rav-Acha. Biofilm interactions in water reuse systems: adsorption of polysaccharide to kaolin. Water Science and Technology. 26,673 (1992). [45] B. Gu, H. E. Doner. The interaction of polysaccharides with Silver Hill illite. Clays and Clay Minerals. 40,151 (1992).

[46] A. J. Simpson, M. J. Simpson, W. L. Kingery, B. A. Lefebvre, A. Moser, A. J. Williams, M. Kvasha, B. P. Kelleher. The application of $1 \mathrm{H}$ high-resolution magic-angle spinning NMR for the study of clay-organic associations in natural and synthetic complexes. Langmuir. 22,4498 (2006).

[47] K. D. Kwon, H. Green, P. Bjoeoern, J. D. Kubicki. Model Bacterial Extracellular Polysaccharide Adsorption onto Silica and Alumina: Quartz Crystal Microbalance with Dissipation Monitoring of Dextran Adsorption. Environmental Science \& Technology. 40,7739 (2006). 